See discussions, stats, and author profiles for this publication at: https://www.researchgate.net/publication/326432052

\title{
A randomised control trial of parent and child training programmes (versus wait list control) for children with ADHD-type behaviours: A pilot study
}

Article in Child Care in Practice · July 2018

DOI: 10.1080/13575279.2018.1481368

\section{CITATION}

1

6 authors, including:

Yvonne Leckey

National University of Ireland, Maynooth

20 PUBLICATIONS 178 CITATIONS

SEE PROFILE

Grainne Hickey

Institute of Child Education and Psychology Europe

24 PUBLICATIONS 186 CITATIONS

SEE PROFILE
181

Sinead McGilloway

Maynooth University Ireland

165 PUBLICATIONS 1,835 CITATIONS

SEE PROFILE

Mairéad Bracken-Scally

Mercy University Hospital

19 PUBLICATIONS 18 CITATIONS

SEE PROFILE

Some of the authors of this publication are also working on these related projects:

Project The THRIVE Project (Training Hope, wellbeing and Resilience in Vulnerable Early school Leavers) View project

INSPIRE Study. INvestigating Social and Practlcal suppoRts at the End of life. View project 


\section{A randomised control trial of parent and child training programmes (versus wait list control) for children with ADHD-type behaviours: A pilot study}

Yvonne Leckey, Sinead McGilloway, Grainne Hickey, Mairead Bracken-Scally, Paul Kelly \& Mairead Furlong

To cite this article: Yvonne Leckey, Sinead McGilloway, Grainne Hickey, Mairead BrackenScally, Paul Kelly \& Mairead Furlong (2018): A randomised control trial of parent and child training programmes (versus wait list control) for children with ADHD-type behaviours: A pilot study, Child Care in Practice, DOI: 10.1080/13575279.2018.1481368

To link to this article: https://doi.org/10.1080/13575279.2018.1481368

曲 Published online: 16 Jul 2018.

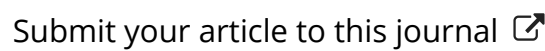

Џ Article views: 66

View Crossmark data 


\title{
A randomised control trial of parent and child training programmes (versus wait list control) for children with ADHD- type behaviours: A pilot study
}

\author{
Yvonne Leckey (D) ${ }^{a}$, Sinead McGilloway ${ }^{a}$, Grainne Hickey ${ }^{a}$, Mairead Bracken-Scally ${ }^{b}$, \\ Paul Kelly ${ }^{b}$ and Mairead Furlong ${ }^{a}$ \\ ${ }^{a}$ Department of Psychology, Maynooth University, Maynooth, Ireland; ${ }^{\mathrm{b}}$ School of Nursing \& Midwifery, Trinity \\ College, Dublin, Ireland
}

\begin{abstract}
Objective: A randomised control trial was conducted to assess whether the combined Incredible Years parent training and child training programmes $(\mathrm{PT}+\mathrm{CT}$ ) led to improvements in ADHD-type behaviours in children, when compared to a PT-only group and a Wait List Control (WLC) group.

Method: Forty-five families with a child aged 3-7 years who displayed ADHD-type behaviours were referred for treatment and randomised to a combined treatment group (PT $+\mathrm{CT} ; n=12$ ), a PT group $(n=19)$ or a WLC group $(n=14)$. Programmes were delivered by community-based organisations. Short-term follow-up (six months) assessments were undertaken with parents and children based on parent reports of child behaviour and parent well-being and behaviour. A qualitative sub-study was also conducted with parent participants $(n=8)$ and programme facilitators $(n=5)$ to explore experiences and views of the combined programme.

Results: Statistically significant differences were found between the PT group and the WLC group with regard to child hyperactivity $(p<0.001)$ and pro-social skills $(p<0.05)$. No significant differences were found between the combined group (PT + CT) and the PT group except for child hyperactivity $(p<0.05)$, which was significantly lower in the PTonly group. Significant effects were found for PT $+C T$ versus WLC on the Strengths and Difficulties Questionnaire Impact subscale only.

Conclusion: These findings suggest that the combined treatment (PT $+\mathrm{CT}$ ) produced little added benefit for child hyperactive/ inattentive behaviour post-intervention despite the very positive views expressed by parents in the qualitative interviews. The PT training alone was more effective in tackling some core ADHD behaviours when compared to the WLC group, but a need for further more large-scale research is indicated.
\end{abstract}

Trial Registration: ISRCTN82596506.

\section{KEYWORDS}

Attention deficit hyperactivity disorder; randomised control trial; parent training; child training; combined treatment

\section{Introduction}

Attention Deficit Hyperactivity Disorder (ADHD) is a chronic and debilitating behavioural disorder that emerges in early childhood and is characterised by maladaptively 
high levels of inattention, hyperactivity and impulsivity (Harpin 2005). ADHD is among the most common mental health disorders of childhood and affects approximately 3-9\% of children and young people in the UK (National Institute for Health and Clinical Excellence [NICE], 2008), with a higher prevalence in males than females (Polanczyk, de Lima, Horta, Biederman, \& Rohde, 2007).

ADHD significantly affects multiple domains of functioning, as well the child's social, educational and family life. Children with $\mathrm{ADHD}$ often present with comorbidities such as oppositional defiant disorder, conduct disorder and learning difficulties (Chronis, Chacko, Fabiano, Wymbs, \& Pelham, 2004; Larson, Russ, Kahn, \& Halfon, 2011), while others can present with internalising symptoms and mood disorder, as well as symptoms of Autistic Spectrum Disorder (ASD; NICE, 2009). Furthermore, children with ADHD are at increased risk of academic failure (Polderman, Boomsma, Bartels, Verhulst, \& Huizink, 2010), social rejection, (de Boo \& Prins, 2007; Mikami \& Lorenzi, 2011), antisocial behaviour/delinquency and substance abuse (Barkley, 2002). Without treatment/intervention, these children are at a long-term risk of negative developmental outcomes, including psychological, interpersonal occupational and economic difficulties in adult life (Barkley, Murphy, \& Fischer, 2008). Family distress and disrupted familial interaction are also common (Tettenborn et al., 2008).

Traditionally, pharmacological treatment/management (e.g. methylphenidate) has been the most commonly reported intervention for children with ADHD (Olfson, Gameroff, Marcus, \& Jensen, 2003; Zuvekas, Vitiello, \& Norquist, 2006); however, ethical issues persist around the use of medication with younger children (NICE, 2008; Taylor et al., 2004). Moreover, psychotropic intervention does not tackle critical secondary issues such as socioemotional and behavioural difficulties and peer problems. Children with ADHD often display negative and non-compliant behaviour and are typically more challenging to parent (Daley et al., 2009). There is also a clear association between poor parenting practices and the severity of ADHD-related behaviours (Modesto-Lowe, Danforth, \& Brooks, 2008), whilst parents' inability to cope with the stress of managing their child's behaviour can result in lax or negative parenting practices (McKee, Harvey, Danforth, Ulaszek, \& Friedman, 2004). For these reasons, psychosocial approaches are now recommended as the first line of treatment for children with ADHD and their families (NICE, 2009); these include cognitive behavioural therapies such as child social skills training and parenting training, family therapy, school-based programmes and psychoeducational interventions.

Group-based parent training programmes, in particular, are recommended as the first course of action for families, and substantial evidence demonstrates the effectiveness of such programmes for children with disruptive behaviour or conduct disorder (e.g. Furlong et al., 2013). A number of studies have also found improvements in parentreported symptoms of $\mathrm{ADHD}$, parenting skills and overall behavioural functioning, as a result of parent training (Chronis et al., 2004; Daley et al., 2014; Fabiano et al., 2009; Sonuga-Barke, Thompson, Abikoff, Klein, \& Brotman, 2006). A relatively recent metaanalytic review reported a moderate effect size for parent training on both child and parent behaviour post-intervention in children with ADHD (Lee, Niew, Yang, Chen, \& Lin, 2012). However, other reviews highlight only limited evidence (Zwi, Jones, Thorgaard, York, \& Dennis, 2011) and a lack of significant effects when based on probably 
blinded assessments, such as teacher ratings or direct observations, rather than parental reports (Sonuga-Barke et al., 2013).

Children with ADHD typically exhibit significant deficits in self-regulation of behaviour and social interaction (Nixon, 2001), resulting in an inability to make or maintain friendships (Hoza, 2007). There is some evidence to suggest that social skills training may be a useful intervention for ADHD (Antshel \& Remer, 2003; Hannesdottir, Ingvarsdottir, \& Bjornsson, 2017), although a lack of well-designed and controlled outcome studies has been noted (de Boo \& Prins, 2007). Such training is typically group-based and focuses on developing and reinforcing appropriate social skills (Spence, 2003) whilst reducing aversive behaviours.

The Incredible Years (IY) Basic Parent Training (Webster-Stratton \& Reid, 2010) (IYPT) has been widely evaluated as an intervention for children with conduct disordered behaviour and has been found to reduce antisocial behaviour, strengthen parental competencies and improve parent-child relationships and child behavioural functioning (e.g. Bywater et al., 2009; Gardner, Burton, \& Klimes, 2006; McGilloway et al., 2012; Menting, de Castro, \& Matthys, 2013; Scott et al., 2001). A small number of studies have also reported positive effects for ADHD behaviour including child inattention and hyperactivity, as well as a reduction in negative parenting practices (Azevedo, Seabra-Santos, Gaspar, \& Homem, 2013; Hartman, Stage, \& Webster-Stratton, 2003; Jones, Daley, Hutchings, Bywater, \& Eames, 2007). Therefore, a combination of parent- and child-focused interventions may potentially lead to better outcomes by simultaneously strengthening parent competencies and enabling parents to reinforce child social skills (Spence, 2003). A small number of studies have assessed, and found positive effects from, the combined IY Basic Parenting Training and Small Group Dinosaur (Dina) programmes in children with conduct problems (Larsson et al., 2009; WebsterStratton, Reid, \& Hammond, 2004; Webster-Stratton, Jamila Reid, \& Stoolmiller, 2008), including those with high levels of hyperactive/inattentive behaviours (Hartman et al., 2003; Webster-Stratton, Reid, \& Beauchaine, 2011). However, there have been very few independent replications of this work outside the U.S., whilst little evidence exists on the effectiveness of the combined IY parent and child training programmes in reducing core ADHD behaviours.

This pilot study involved a randomised control trial to investigate the short-term effectiveness of the Incredible Years (IY) Basic Parent Training (PT) and a combination of the PT and IY child-focused Small Group Dinosaur Programme (PT + CT), when compared to a wait list control (WLC) group. We hypothesised that both PT alone and PT + CT would lead to reductions in hyperactive, impulsive behaviour and parental distress when compared to the WLC group and that the PT + CT group would be superior to the PT alone. We were also interested in the experiences of parents who attended the PT + CT group, to explore their perceptions of the parent and child programmes and whether any benefits were evident in dealing with their child's core ADHD behaviours, particularly as the combined treatment is considered optimal for managing child behavioural problems (Webster-Stratton et al., 2011). Therefore, a small qualitative study was also undertaken with a sample of parents and facilitators to identify benefits and/or challenges associated with the content and delivery of the combined $(\mathrm{PT}+\mathrm{CT})$ programme. 


\section{Method}

\section{Participants}

Fifty-eight families were referred to the study through Health Board waiting lists, Child and Adolescent Mental Health Services, local schools and community-based family centres, or by self-referral. Participants were included in the trial if: (a) the person was the primary caregiver of the child; (b) the child was aged 3-7 years; ${ }^{1}$ (c) the primary referral reason related to persistent hyperactivity, inattention and/or impulsive behaviours; (d) the child scored above the cut-off $(>17)$ on the screening measure, the Werry-WeissPeters Activity Rating Scale (WWPARS; Werry, 1968); (e) the child was not receiving any ADHD medication prior to, or for the duration of, the research; and (f) the parent or child had not previously attended any IY programmes. Of the 58 families who agreed to participate in the study, 13 (22\%) did not meet the eligibility criteria. Five children were outside the stated age range, two of the children had a diagnosis of ASD, five children scored below the required threshold on the WWPARS and one parent had custody of her child at weekends only. Forty-five families were subsequently eligible for inclusion in the study (Figure 1).

\section{Randomisation and blinding}

Parent and child dyads were randomly allocated on a 2:1 basis to the intervention group (PT or PT + CT, $n=31$ ) or a wait-list control group (WLC, $n=14$; Figure 1 ). Randomisation was carried out on a 2:1 basis by an independent statistician using a computer-generated random number sequence. This allowed for the inclusion of a larger intervention group (i.e. PT + CT or PT), which is ethically desirable in evaluations within a community setting, whilst also ensuring that fewer people were placed on a waiting list. The unit of randomisation was the parent-child dyad and participants were block randomised by area to ensure that parents attended the programme in their locality. An administrator subsequently informed participants of their treatment allocation. While the administrator was also a researcher on the study, all other researchers were unaware of group allocation and parents were asked not to inform researchers at follow-up assessment as to their allocated group to minimise potential basis (where possible). Of the 12 parent-child dyads randomised to the PT $+\mathrm{CT}$ group, six children were allocated to a pre-school group (2.9 years -4.5 years) and six to a primary school group (4.8-6 years).

\section{Procedure}

Parents/guardians of participating children were provided with information sheets and invited to give their written informed consent for their child to participate. Data were collected in parents' homes at two time points: baseline (prior to intervention) and six months later (January to September) following intervention delivery. The majority of participating parents (i.e. who took part in both the training and the research) were mothers (42/45) and pre- and post-measures were completed by the same participant at each timepoint. Parents and children in the PT $+\mathrm{CT}$ and PT groups received the intervention during the six month interim period between data collection points. Parents allocated to the WLC group were offered the parent programme after the six month follow-up. 


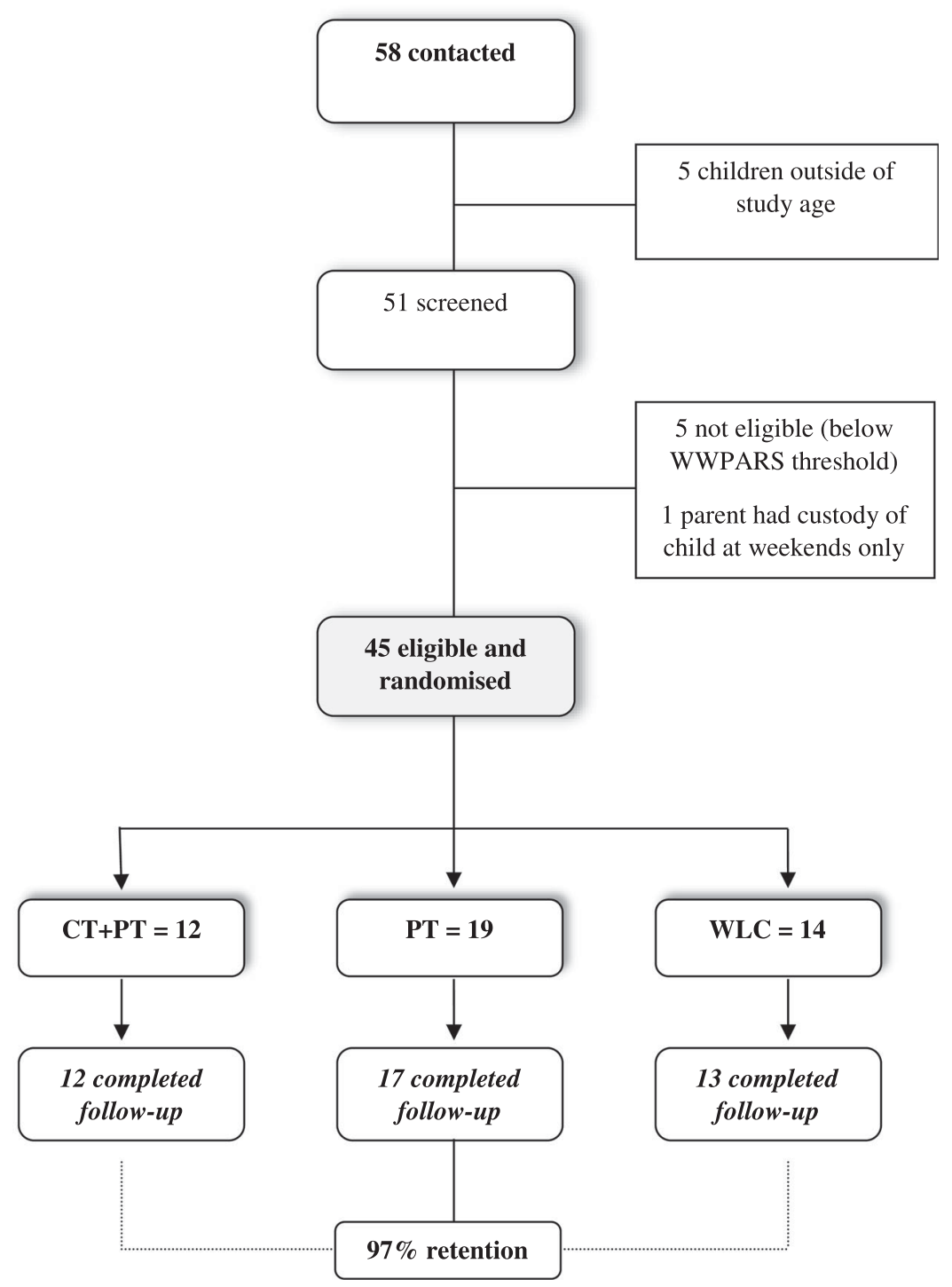

Figure 1. Flowchart of participants entering the trial.

Following programme completion, a small qualitative study was undertaken with a sample of parents $(n=8)$ and facilitators $(n=5)$ from the combined PT + CT group to explore programme experiences and/or challenges associated with combined delivery of the parent and child programmes. One-to-one interviews were conducted with parents in their homes to explore their perceptions of their child's hyperactivity and inattention issues, as well as their experiences and views of the combined programme. A focus group was also conducted with facilitators of the child programme to assess their perceptions of programme implementation and its suitability in addressing ADHD behaviours. Interviews were recorded (with consent), transcribed verbatim and analysed using standard thematic analysis. The study received ethical approval from Maynooth University Social Research Ethics Sub-Committee. 


\section{Measures}

A number of psychometric measures were used to assess key outcomes, including child conduct problems and social competencies, as well as parent competencies and psychological well-being. Demographic and background information on parents and children was collected at baseline using a Profile Questionnaire; this questionnaire contains a number of both closed and open-ended questions which gather demographic information on families including employment status, income and health characteristics. The Profile Questionnaire was previously used in an IY evaluation for children with clinically significant conduct problems (McGilloway et al., 2012). Several parent-report measures were used to assess the nature and severity of child hyperactivity, inattention and impulsivity. Levels of parental psychopathology and dysfunctional parent-child interactions were also assessed to identify any changes in parental distress and competency. All measures were administered pre-intervention and at six month follow-up. The reliability of all measures was assessed using Cronbach's alpha.

The WWPARS (Werry, 1968) was the primary outcome measure; this measure was chosen to assess the degree of a child's hyperactivity and attention problems in different settings. Furthermore, the WWPARS focuses strictly on activity levels across various settings and has been found to discriminate between hyperactive and normal children (Sprague, Barnes, \& Werry, 1970). Secondary measures included the Conners Parent Rating Scale (3rd edition) Short Form (CPRS-SF; Conners, 2008), which measures hyperactive/inattentive behaviours including overactivity, inattention, restlessness and emotional reactivity and the Strengths and Difficulties Questionnaire (SDQ; Goodman, 1997), which consists of five subscales relating to hyperactivity, conduct problems, peer problems, emotional symptoms and prosocial behaviour. Good internal consistency was found for all three measures (WWPARS, 0.83; Conners, 0.94; SDQ, 0.6). Parenting behaviour, distress and well-being were measured using the Parenting Scale (Arnold, O'leary, Wolff, \& Acker, 1993) and the Parenting Stress Index - Short Form (Abidin, 1990). The Parenting Scale is a 30 item questionnaire which has been validated for use with parents of ADHD children (Harvey, Danforth, Ulaszek, \& Eberhardt, 2001) and was used to assess dysfunctional discipline practices, including "Overreactivity" (authoritarian/harsh discipline), "Laxness" (permissive discipline) and "Verbosity" (overly long reprimands/responses). The 36-item Parenting Stress Index - Short Form (Abidin, 1990) was used to measure the distress experienced by parents in their parenting role, as well as dysfunctional parent-child interactions. Cronbach's alphas were 0.50 and 0.93 respectively.

\section{Intervention and setting}

The IYPT (Webster-Stratton, 2007) is a group-based intervention guided by the principles of behavioural and social learning theory and comprising 20 weekly 2-2.5 hour sessions. Group discussions and role plays are used in combination with DVD material to illustrate various parenting and discipline strategies. The programme promotes positive parenting techniques, such as child-directed play and encouragement to foster child cooperation and to strengthen parent-child relationships. Child problem behaviours are addressed by encouraging parents to reinforce positive pro-social behaviour and manage inappropriate 
behaviour using non-aversive discipline strategies. For the purposes of this study, the structure and methods of the programme were slightly enhanced to address the high levels of hyperactivity and inattention; these included more role-plays and group activities to model and practise skills to promote positive behaviour. While programme modifications are not recommended, especially as fidelity is a key component for effective implementation, modifications have been made when treating children with ADHD (Webster-Stratton \& Reid, 2014). Parents were also encouraged to establish more regular and consistent routines and to set clear limits and boundaries. Facilitators made weekly phone calls to problem-solve and encourage the application of skills in the home.

Parents in the PT + CT group attended the parent training while their child simultaneously attended CT training. The CT component (Webster-Stratton, 2005) comprises 18 weekly 2 hour sessions and includes coaching, the use of puppets, video vignettes and homework assignments to promote child socioemotional and self-regulatory skills. The Dina Dinosaur programme can be modified to address the needs of children with ADHD, oppositional defiant disorder and ASD (Webster-Stratton \& Reid, 2008) so that the intervention is developmentally and therapeutically more appropriate. Children with ADHD have poor focus and attention as well as high levels of impulsivity so the modified version used here allows for limited attention span and the need for greater physical movement amongst children. It also places greater emphasis on key deficits such as emotional regulation and friendship and on reinforcing appropriate communication skills. The programme is recommended for children within the pre-school and schoolage groups, from 4 to 8 years, and accommodates the varying developmental levels of children by ensuring that developing peer models are included in each group in order to model appropriate self-regulation and behaviour with younger children (Webster-Stratton \& Reid, 2003).

\section{Treatment delivery and integrity}

Four programmes were delivered by three community and voluntary organisations in local, community-based settings such as family resource centres and schools. Group sessions were held at a time and a place that suited participants. Organisations had regular engagement with families in the intervention groups. All training programmes were delivered by at least two facilitators who had received extensive training in the context and techniques of the intervention. The leaders had varied backgrounds including psychology, counselling and education or related fields. While the programme content was slightly modified to address child ADHD, core behaviours and programme components were covered in every session and programme fidelity was assessed by means of session checklists and participant satisfaction questionnaires. Owing to limited resources, it was not possible to carry out any independent checks on fidelity, nor was programme delivery objectively assessed for the same reason. During course delivery, the group leaders received regular supervision and support from a certified independent IY trainer and attended weekly meetings to assess progress and address issues that may have arisen during group sessions. Free transportation and refreshments, crèche facilities or financial reimbursement for childcare were provided to improve engagement and reduce barriers to participation. 


\section{Treatment attendance}

PT group $(n=19)$ : the average number of sessions attended by the 19 parents in the PT group was $10.05(\mathrm{SD}=7.7)$ out of 20 sessions. In total, $56 \%$ of parents $(11 / 19)$ attended 10 or more sessions. Five parents (26\%) did not attend any sessions. The average number of sessions attended by parents was $3.18(\mathrm{SD}=6.1)$. Compliance with the programme was deemed to be acceptable if parents had attended 10 of the 20 sessions, with $83 \%$ of parents attending an average of 15 sessions.

$\mathrm{PT}+\mathrm{CT}$ group $(n=12)$ : mean attendance on the parenting programme was 15 sessions $(\mathrm{SD}=5.9)$, indicating that attendance was higher for this group than for the PT cohort alone. For the child training programme, children attended on average 13/18 sessions $(\mathrm{SD}=6.3)$, with three-quarters $(75 \% ; 9 / 12)$ attending 9 or more sessions. One child attended 3 sessions.

\section{Analysis}

Assessments of child and parent adjustment were conducted using parent-report measures at baseline and at 6 months post-intervention. Baseline comparisons between groups were carried out using independent samples $t$-tests and chi-square. A strict intention-to-treat analysis was carried out whereby all participants were included in the analysis regardless of programme attendance. No change from baseline was assumed for participants who were lost to follow-up. At the six month assessment, three parents (7\%) were lost to follow-up, indicating a 93\% retention rate. An analysis of covariance (ANCOVA) was carried out to examine post-intervention differences between conditions (i.e. PT versus WLC; PT + CT versus WLC; PT versus PT + CT), controlling for baseline score, training group and intervention status. Effect sizes were calculated using Cohen's guidelines whereby a small effect size is denoted by approximately $0.3,0.5$ denotes a medium/moderate effect size while 0.7-0.8 denotes a large effect size (Cohen, 1988). A per-protocol analysis was not conducted as only three participants were lost to follow-up,

\section{Results}

\section{Participant characteristics}

Personal and demographic characteristics of the sample are reported in Table 1. The index children were predominantly male $(78 \%)$ with a mean age of 57 months $(\mathrm{SD}=15.6$ months). Study parents included 42 mothers and three fathers, most of whom were married $(28 / 45 ; 62 \%)$. A high proportion of families were socioeconomically disadvantaged; approximately $69 \%$ of the total sample were at risk of poverty based on income and family size. A more precise "socioeconomic disadvantage" score was calculated, based on the demographic data relating to: employment status; parental status (lone parent versus married/co-habiting); size of family; parental education; quality of housing; and levels of criminality in the participants' area of residence with a score of 2 or more indicating social disadvantage. In total, $44 \%(20 / 45)$ of participants were considered disadvantaged (mean $=1.5$, standard deviation $=0.9$ ) according to these characteristics. 
Table 1. Demographic characteristics at baseline (unless otherwise noted, numbers are frequencies (\%)).

\begin{tabular}{lccc}
\hline & WLC $(n=14)$ & PT $(n=19)$ & PT + CT $(n=12)$ \\
\hline No. (\%) boys & $10(71)$ & $15(79)$ & $10(83)$ \\
Single parent & $6(43)$ & $4(21)$ & $7(58)$ \\
Separated/divorced & $1(7)$ & $4(21)$ & $0(0)$ \\
Large family ( $\geq 3$ children) & $6(43)$ & $8(42)$ & $6(50)$ \\
History of depression & $9(64)$ & $11(58)$ & $10(83)$ \\
At risk of poverty & $11(79)$ & $14(74)$ & $6(50)$ \\
Primary carer left school before finishing secondary & $9(69)$ & $3(17)$ & $3(25)$ \\
Mean (SD) age of primary care giver (years) at birth of first child & $24.2(6.2)$ & $24.6(5.7)$ & $26.1(4.7)$ \\
Mean age (SD) of child in months (SD) & $58.8(16.5)$ & $57.1(17.1)$ & $56.4(13.7)$ \\
Socioeconomic disadvantage score & & & \\
$\quad \geq 2 / 6$ & $7(47)$ & $7(39)$ & $6(50)$ \\
$\quad$ Mean (SD) no. & $1.5(1.1)$ & $1.4(0.8)$ & $1.5(0.8)$ \\
Risk factors for conduct disorder ${ }^{b}$ & $12(86)$ & $12(67)$ & $9(90)$ \\
$\quad \geq 2 / 5$ & $2.6(1.0)$ & $2.4(1.5)$ & $2.8(0.8)$ \\
$\quad$ Mean (SD) no. & & & \\
\hline
\end{tabular}

Note: No significant differences between groups

${ }^{a}$ Employment status; parental status (lone versus married/co-habiting); size of family; parental education; quality of housing; and levels of criminality in the participant's area of residence.

${ }^{\mathrm{b}}$ Single parenthood; teenage parenthood; parental depression; family poverty; and parental history of drug abuse or criminality.

At baseline, parents (on average) reported clinically significant levels of stress and high levels of hyperactivity and attention deficit problems in their children, as well as externalising, aggressive and oppositional problems. A risk factor score ranging from 0 to 5 was calculated on the basis of several variables known to increase the risk of conduct disorder, including single parenthood, teenage parenthood, parental depression, family poverty and parental history of drug abuse or criminality (Webster-Stratton, 1998). In total, 73\% of child participants experienced two or more risk factors indicating a significant proportion at increased risk of serious psychological distress. There were no differences at baseline between participants in the three experimental conditions with respect to demographic characteristics, or scores on psychometric measures.

\section{Treatment outcomes}

\section{Child outcomes}

PT versus WLC: no between-group differences were found in the primary outcome measure (the WWPARS). However, statistically significant differences emerged between the PT group and the WLC group on hyperactivity, as measured by both the SDQ $(p<0.001)$ and Conners ADHD index subscales $(p<0.05)$ (Table 2$)$. Thus, parents who participated in the parent training rated their child's behaviour as less hyperactive, inattentive and oppositional post-intervention when compared to the WLC group. Children in the PT group also demonstrated significantly higher postintervention levels of pro-social behaviour and social competence $(p<0.05$; as measured by the SDQ Pro-social subscale).

PT + CT versus WLC: there were no significant differences in outcomes except for the SDQ Impact subscale $(p<0.05)$, which indicated lower levels of child distress and social impairment post-intervention for the combined group when compared to the control group (Table 2). No further between-group differences were found on child outcomes. 
Table 2. Summary of child measures and baseline and 6-month follow-up.

\begin{tabular}{|c|c|c|c|c|c|c|c|c|c|}
\hline & \multicolumn{2}{|c|}{ WLC $(n=14)$} & \multicolumn{2}{|c|}{ PT $(n=19)$} & \multicolumn{2}{|c|}{$\mathrm{PT}+\mathrm{CT}(n=12)$} & \multicolumn{3}{|c|}{ Effect size $(d)$} \\
\hline & $\begin{array}{l}\text { Baseline, } \\
\text { mean (SD) }\end{array}$ & $\begin{array}{l}\text { Follow-up, } \\
\text { mean (SD) }\end{array}$ & $\begin{array}{l}\text { Baseline, } \\
\text { mean (SD) }\end{array}$ & $\begin{array}{l}\text { Follow-up, } \\
\text { mean (SD) }\end{array}$ & $\begin{array}{l}\text { Baseline, } \\
\text { mean (SD) }\end{array}$ & $\begin{array}{l}\text { Follow-up, } \\
\text { mean (SD) }\end{array}$ & PT versus WLC & $\mathrm{PT}+\mathrm{CT}$ versus $\mathrm{WLC}$ & $\mathrm{PT}$ versus $\mathrm{PT}+\mathrm{CT}$ \\
\hline SDQ Total & $18.6(5.2)$ & $17.9(5.9)$ & $21.6(5.7)$ & $18.3(7.7)$ & $22(6.2)$ & $21.3(5.2)$ & 0.44 & -0.19 & -0.63 \\
\hline SDQ Emotional Symptoms & $3.1(1.7)$ & $2.7(2.8)$ & $4.4(2.2)$ & $4.3(2.9)$ & $4.4(2.6)$ & $4.3(2.6)$ & -0.29 & -0.3 & -0.01 \\
\hline SDQ Conduct Problems & $4.9(2.2)$ & $5(2.1)$ & $4.9(2.3)$ & $4.3(2.1)$ & $4.9(2.3)$ & $4.8(3)$ & 0.42 & -0.12 & -0.54 \\
\hline SDQ Hyperactivity & $7.4(1.7)$ & $7.6(1.9)$ & $8.6(1.7)$ & $6.4(3)$ & $8.5(1.5)$ & $8.4(1.6)$ & $1.34^{* *}$ & 0.11 & $-1.22^{*}$ \\
\hline SDQ Peer Problems & $3.1(2.4)$ & $2.6(2.2)$ & $3.6(2.1)$ & $3.3(1.9)$ & $4.2(2.8)$ & $3.8(2)$ & -0.3 & -0.33 & -0.04 \\
\hline SDQ Pro-Social & $6.6(2.5)$ & $6.4(2.6)$ & $5.8(2.9)$ & $7.1(2.1)$ & $6.2(2.3)$ & $6.8(2.6)$ & $-0.72^{*}$ & -0.25 & 0.47 \\
\hline SDQ Impact Supplement & $3.1(2.5)$ & $3.7(3.0)$ & $3.7(3.0)$ & $2.8(2.7)$ & $4.9(2.3)$ & $3.3(2.5)$ & 0.66 & $0.86^{*}$ & 0.2 \\
\hline WWPARS & $37.6(9.7)$ & $32.6(12.5)$ & $33.2(8.5)$ & $26.2(12.8)$ & $35.5(9.6)$ & $29.6(11.4)$ & 0.32 & 0.15 & -0.17 \\
\hline Conners Oppositional & $11(5.6)$ & $11.5(5.5)$ & $12(4.4)$ & $9.7(5.8)$ & $12.8(4.4)$ & $11.9(5.3)$ & 0.65 & 0.26 & -0.38 \\
\hline Conners Cognitive & $11.5(6.1)$ & $12(4.9)$ & $12.2(4.9)$ & $10.1(6.1)$ & $13(4.8)$ & $12.2(3.7)$ & 0.62 & 0.23 & -0.39 \\
\hline Conners Hyperactivity & $12.9(4)$ & $12.3(4.3)$ & $14.1(3.8)$ & $10.6(5.7)$ & $14.2(3.1)$ & $13.3(3.2)$ & 0.70 & 0.01 & -0.69 \\
\hline Conners ADHD Index & $24.7(7.7)$ & $24.8(9.2)$ & $26.8(7.8)$ & $21.3(9.9)$ & $26.8(6.2)$ & $26.1(5)$ & $0.78^{*}$ & 0.05 & -0.73 \\
\hline Conners Total & $54.6(17.2)$ & $55(20.2)$ & $59.2(16.3)$ & $44.8(22.1)$ & $60.9(13.2)$ & $51.3(15.8)$ & $0.82^{*}$ & 0.50 & -0.32 \\
\hline
\end{tabular}

${ }_{* *}^{*} p<0.001$

$\mathrm{SDQ}=$ Strengths and Difficulties Questionnaire; WWPARS = Werry-Weiss-Peters Activity Rating Scale; Conners = Conners Parent Rating Scale-SF (3rd edn). 
PT versus PT + CT: significant differences favouring the PT-only group were found on the SDQ hyperactivity subscale, when compared to those in the PT + CT group. No other statistically significant differences between the groups were identified (Table 2).

\section{Parent outcomes}

PT v WLC: a number of significant differences emerged between the PT and WLC groups on self-reported parenting practices and use of discipline (as measured by the Parenting Scale) at the six month follow-up (Table 3). Parents in the PT group, when compared to their WLC counterparts, used fewer harsh disciplining measures and showed improved parental instruction and verbal interaction with their child. Lax parental discipline was also significantly lower amongst parents in the PT group $(p<0.05)$, thereby indicating that they used less permissive and inconsistent discipline techniques post-intervention. There were no post-intervention differences between the PT and WLC groups on measures of parental distress.

PT + CT versus WLC: no statistically significant differences were found between the PT + CT and WLC groups for parental well-being or disciplining strategies (Table 3).

PT + CT versus PT: no improvements were evident in parenting behaviour and wellbeing or parent child relationship between the combined group and parent group (Table 3).

\section{Qualitative findings-experiences of the PT + CT intervention}

Overall, parents who participated in the PT + CT training expressed a high level of satisfaction with programme components, such as positive praise, learning to play, techniques to manage child misbehaviour, DVD clips, question and answer sessions. Parents felt that the group dynamic provided an environment of social and emotional support where participants could comfortably share their experiences.

\section{Improved child behaviour}

All but one parent reported that their child's hyperactivity and inattentiveness had improved considerably post-programme. Parents also described improved prosocial skills, as well as a greater ability to follow instructions. Three parents remarked that their child's behaviour had improved in school while another two parents noted fewer tantrums in their children and a greater ability to manage their emotions. Overall, many parents rated their child's behaviour as calmer, more relaxed and less agitated:

[He] gained so much in Dina school. He learned so many skills that he will need to bring with him going forward in the future... It has made a huge impact on [his] life. He is like a different child. [Mother of 6-year-old boy]

[He] learned to calm himself down. So he learned to listen to me a lot more and learned to respect what I'd say to him. [Mother of 5-year-old boy]

\section{Changes in parental behaviour}

All parents reported improved parental competencies and reduced stress levels as a consequence of the programme. There was also evidence of greater positive interaction with their child, specifically in terms of clearer parent-child communication and more directed 
Table 3. Summary of parent measures and baseline and 6-month follow-up.

\begin{tabular}{|c|c|c|c|c|c|c|c|c|c|}
\hline & \multicolumn{2}{|c|}{ WLC $(n=14)$} & \multicolumn{2}{|c|}{ PT $(n=19)$} & \multicolumn{2}{|c|}{$\mathrm{PT}+\mathrm{CT}(n=12)$} & \multicolumn{3}{|c|}{ Effect size $(d)$} \\
\hline & $\begin{array}{l}\text { Baseline, mean } \\
\text { (SD) }\end{array}$ & $\begin{array}{l}\text { Follow-up, mean } \\
\text { (SD) }\end{array}$ & $\begin{array}{l}\text { Baseline, mean } \\
\text { (SD) }\end{array}$ & $\begin{array}{l}\text { Follow-up, mean } \\
\text { (SD) }\end{array}$ & $\begin{array}{l}\text { Baseline, mean } \\
\text { (SD) }\end{array}$ & $\begin{array}{l}\text { Follow-up, mean } \\
\text { (SD) }\end{array}$ & $\begin{array}{l}\text { PT versus } \\
\text { WLC }\end{array}$ & $\begin{array}{c}\mathrm{PT}+\mathrm{CT} \text { versus } \\
\text { WLC }\end{array}$ & $\begin{array}{l}\text { PT versus PT } \\
+\mathrm{CT}\end{array}$ \\
\hline PSI Total & $101.9(26.4)$ & $100.4(24.5)$ & $97.9(20.6)$ & $91.5(16.7)$ & $100.2(19.5)$ & $101.3(29.5)$ & 0.35 & -0.11 & -0.46 \\
\hline PSI Parental Distress & $33.4(10)$ & $32.4(10.4)$ & $30.8(11.2)$ & $29.1(9)$ & $34.6(10.5)$ & $33.8(12)$ & 0.19 & -0.09 & -0.29 \\
\hline $\begin{array}{l}\text { PSI Parent-Child } \\
\text { Dysfunctional Interaction }\end{array}$ & $27.5(10.1)$ & $28.1(8.5)$ & $26.8(8.6)$ & $25.8(6.4)$ & $26.1(9.7)$ & $27.8(11.2)$ & 0.32 & -0.09 & -0.41 \\
\hline PSI Difficult Child & $41(10.9)$ & $39.9(10.1)$ & $40.4(7.8)$ & $36.6(9.5)$ & $43.4(8.8)$ & $39.7(10.4)$ & 0.36 & 0.23 & -0.13 \\
\hline Parenting Scale Total & $105.4(17.7)$ & $101.9(24.5)$ & $89.7(21.1)$ & $74.2(21.7)$ & $97.2(26.2)$ & $85.3(28.3)$ & $0.86^{*}$ & 0.57 & -0.29 \\
\hline Parenting Scale Laxness & $38.7(14.7)$ & $39.3(16.9)$ & $29.7(14.7)$ & $23.7(9.3)$ & $33.9(13.7)$ & $29.8(12.8)$ & $1.09^{*}$ & 0.7 & -0.38 \\
\hline Parenting Scale Overreactive & $28.7(10.1)$ & $25.4(7.3)$ & $25.2(10)$ & $20.8(8.1)$ & $27.7(9.5)$ & $26.4(10.1)$ & 0.4 & -0.25 & -0.65 \\
\hline Parenting Scale Verbosity & $30.4(7.2)$ & $30.4(7.6)$ & $27.7(6.3)$ & $22(7.8)$ & $26.2(5.5)$ & $23.2(7.2)$ & $1.01^{*}$ & 0.75 & -0.26 \\
\hline
\end{tabular}

${ }^{*} p<0.05$.

PSI = Parent Stress Index. 
parent-child play. Parents described behavioural management techniques as being particularly useful in promoting good child behaviour and dealing with hyperactivity. These included: the use of praise; goals and reward charts; one-on-one play sessions; and use of time out. In general, techniques to promote positive behaviour and the use of positive praise were considered extremely beneficial in managing misbehaviour:

I loved learning about the positive praise, the praise worked so well in this house. [Mother of 6-year-old boy]

Importantly, the programme allowed parents an opportunity to reflect on their parenting techniques, particularly how their behaviour influenced that of their child:

It helped me realise I might have been making it worse so it helped me realise that I had to change myself as well as him. [Mother of 5-year-old boy]

Parents also reported continued implementation of positive parenting skills after programme completion and particularly during playtime. Nevertheless, sustaining these changes posed challenges for some parents. For example, two had experienced major upheavals in their home life, which were perceived as impacting negatively on their child's behaviour. Moreover, four participants felt the availability of a further booster session/refresher course would help to consolidate programme learning.

\section{Parents' perceptions of the combined delivery of PT and CT}

Most parents felt the simultaneous delivery of the parent and child training programmes led to substantial benefits:

It is like he got a double whammy, and the skills that he learned and the skills that I learned have just worked so well together for both of us so it has been a really, really positive thing in our lives. I would say maybe if they were done at different times it wouldn't have been as successful. [Mother of 6-year-old boy]

I found doing a parenting programme while he was in the Dina worked because both of us was getting taught at the same time. I do think that you needed two together. [Mother of 7year-old boy]

One parent, however, remarked on a "disconnect" between the parent and child programme and two parents commented on the lack of information and feedback on their child's progress. Other concerns which were raised by some of the parent participants concerned the age-appropriateness of the child programme and the ability of their children to fully comprehend programme content. Two parents felt the child training was limited in addressing ADHD-type behaviours, such as hyperactivity and impulsiveness.

I think with his condition he is just hyper; he is always going to be hyper more so than normal children. [Mother of 6-year-old boy]

\section{Facilitators' perceptions of the combined programme}

Facilitators' reports highlighted potential gaps in parents' understanding of the child programme and how the principles should be implemented at home. Facilitators also felt that more interaction with parents regarding the specific techniques of the CT programme could have led to further positive child outcomes. Although this finding is inconsistent 
with the majority of parents, it is possible that there was insufficient integration between the PT and CT elements and that more communication and interaction between CT facilitators and parents would have been useful.

The management of difficult child behaviour during the delivery of the CT programme posed challenges for facilitators and especially for children with co-morbid diagnoses. Facilitators also felt that the language used in the CT programme was potentially too advanced for the pre-school group and that these children may not have had the necessary communication and language skills to listen and follow directions adequately. It was also suggested that, while the puppets worked well with the younger children, older children were unlikely to engage with them and, therefore, responded less positively to their use. Despite this, facilitators reported that themes concerning emotional responses, problem solving and self-regulation, were particularly useful for children with ADHD-type behaviours. The facilitators also recommended greater flexibility in programme implementation and adaptation in order to cope with persistent inattention difficulties. Follow-up sessions or booster sessions were also highly recommended to sustain programme benefits.

\section{Discussion}

The aim of this pilot study was to assess the effectiveness of the combined IY parent and child training, when compared to a parent-only and a wait list control group, in addressing core ADHD-type behaviours in children aged approximately 3-7 years. The findings in relation to parent and child outcomes highlight the potential effectiveness of the IYPT intervention in improving some ADHD behaviours, as well as social skills more generally. Our findings are broadly comparable with the very small number of studies which have explored the effectiveness of the IYPT programme for parents in Portugal (Azevedo et al., 2013), Wales (Jones et al., 2007) and in the U.S. (Hartman et al., 2003); these studies also found statistically significant reductions in hyperactive/inattentive behaviours post-intervention. In terms of secondary outcomes in the current study, the PT-only intervention showed large effect sizes with regard to positively impacting self-reported parenting skills, whereby parents reported using lax and lengthy verbal reprimands less frequently. Likewise, Azevedo et al. (2013) demonstrated improvements in over-reactivity and verbosity practices, while Hartman et al. (2003) found reductions in negative parenting behaviours based on independent observation.

However, the study hypothesis was only partially (or weakly) supported, in that children in the combined PT + CT group did not fare better (on average) than those in WLC group, other than on the SDQ Impact scale, which demonstrated significantly lower levels of child distress and social impairment in the intervention group. Furthermore, in contrast to a U.S.-based, albeit larger, study $(n=99)$ by Webster-Stratton et al. (2011), fewer treatment effects were found for the combined group compared with the PT-only group. Children in the PT-only condition showed greater improvements than their combined group counterparts, but only with regard to hyperactivity (as measured on the SDQ subscale) and, while parenting behaviour improved, it was not found to be statistically significant. These findings seem surprising given the higher compliance rate for parents in the combined group (15 sessions on average; children attended an average of 13 sessions), when compared to the PT-only group (10 sessions on average). However, the lack of reported programme effects for the combined treatment group is 
consistent with Larsson et al. (2009), who found no significant differences between two intervention groups (PT versus PT $+\mathrm{CT} ; n=47 / \mathrm{n}=52$ ) when compared to a WLC group $(n=28)$. The authors suggested that cultural differences and a shorter programme duration (12-14 weeks) may have been influential factors, although our study had a greater number of sessions in the parent programme (20 weeks), as well as a higher attendance rate for the combined treatment. Importantly, however, the qualitative findings indicate high levels of satisfaction with the combined intervention, suggesting that the study may not have been sufficiently powered to detect differences between the two groups.

Despite the benefits reported by the combined group in the qualitative study (e.g. regarding parent-child relationships and improvements in parenting confidence and competence), it is also possible that these parents may have expected greater improvements in their child's behaviour as a consequence of the child training. It is also notable that, while most parents reported improvements in hyperactive/inattentive behaviour, in two cases this was tempered by a perception that the child's hyperactivity was somehow intrinsic to their nature, and that the programme was limited in addressing ADHD-type behaviours. Whilst the lack of any effect on the primary outcome measure may also suggest that the WWPARS was less sensitive to change over time, it may well be that the intervention was less effective in tackling the hyperactive behaviours of ADHD. A need for further research is indicated.

The collective findings reported here also raise questions about the suitability of the combined programme for very young children. Both parents and facilitators felt that the age of children within the child training group was problematic owing to the difficulties amongst the younger children in comprehending concepts and following instruction. The child Dina programme is recommended for children aged 4-8 years and, here, seven of the 12 children were at the very young end of the age spectrum (i.e. aged 4 or under); three children were aged 3 years and under and, as such, may have lacked the cognitive and socioemotional skills to participate fully. Webster-Stratton and Reid (2003) recommends a mix of ages in order that more mature children can model behaviour to the youngest members of the group. Arguably though, the predominance and relative immaturity of the younger children in the current study and their inability to self-regulate meant that they were less likely to benefit from the child training programme than their older counterparts.

The lack of positive effects in the combined treatment group is particularly surprising given the high levels of programme satisfaction reported by participants in the qualitative study. Owing to resource constraints, we were unable to conduct a qualitative study with parents and facilitators from the parent-only group. Nonetheless, our findings are similar to those of Stewart-Brown et al. (2004), who found a similar disconnect, in a one-year follow-up of the IYPT, between their quantitative and qualitative findings. The latter indicated improvements in child behaviour as well as in parental competencies and mental health, but the authors surmised that the benefits were not sufficiently large to reflect a change in the quantitative scores (Stewart-Brown et al., 2004). Similarly, despite the positive results reported in our qualitative study, there were no statistically significant positive outcomes for parents on any of the parental measures administered to the combined treatment group. Despite this, the qualitative findings revealed how some parents in the study became more aware of the impact of their own parenting behaviour on that of their child, with one parent recognising how she too was "part of the problem". By identifying and 
addressing their own negative parenting techniques, parents felt more in control, were more aware of how they interacted with their child and had more realistic expectations of their child's behaviour. Finally, a number of benefits were reported, particularly in terms of better coping skills and reduced stress, thereby highlighting the potential mental health benefits of participating in a parenting programme. Indeed, parent and child interventions are likely to provide therapeutic benefits beyond ADHD symptoms and offer a suitable alternative to pharmacological treatment (Tarver, Daley, \& Sayal, 2014).

The present study - which includes both quantitative and qualitative findings - makes an important contribution to the literature on parenting and child supports as a treatment for ADHD behaviours. The randomised control trial is one of only a very small number, to date, which have examined the effectiveness of: (1) parent training for children with ADHD-type behaviours; and (2) a combined intervention of parent-training programme and child-training programme for this important sub-group. The qualitative results which helped to supplement and amplify the randomised control trial findings were particularly important in elucidating parents' and facilitators' views on programme content and child outcomes, albeit only for the combined treatment group. Stringent quality control procedures were put in place to ensure the quality of all data collected and researchers were blind to treatment allocation. No children in the study were prescribed medication throughout the duration of the study.

There are also a number of limitations to this study. The study sample is relatively small, which may have reduced statistical power and underestimated the clinical effectiveness of the programme. Furthermore, we were unable to undertake a qualitative study with the parent-only group, which may have shed some light on why these participants experienced greater improvements overall when compared to the combined treatment group. In addition, we were unable to assess the longer-run effects of the intervention, which may have identified whether any gains reported by parents were maintained or emerged over time. Lastly, only parent-report measures were used to assess child and parent outcomes and it was not possible, therefore, to carry out independent observations.

Overall, the combined findings from this pilot study suggest significant benefits of a group-based behavioural parent training programme for children presenting with ADHD behaviours. However, the effectiveness of the combined parent training and child social skills training programme was less clear. The qualitative findings highlight perceived behavioural change amongst parents and children in the combined group, as well as high levels of programme satisfaction; this may suggest possible gaps in implementation between the parent and child programmes, thereby reducing the overall effectiveness of the programme. Furthermore, the manner in which parenting programmes are implemented is critical to their success. Our findings suggest that greater coordination and collaboration may be required with regard to the simultaneous delivery of the parent and child training programmes to ensure more effective implementation and consistency of techniques in order to properly address child behaviour. Further large-scale evaluations are needed to explore the potential benefits or otherwise of the child training in addressing core ADHD behaviours.

In summary, an evidence-based, parent-training programme, such as the IYPT, is likely to result in significant improvements in child behaviour and parenting competency, and represents an important, "first-line" intervention for children with elevated levels of hyperactivity and inattention. 


\section{Ethical approval}

All procedures performed in studies involving human participants were in accordance with the ethical standards of the institutional and/or national research committee and with the 1964 Helsinki declaration and its later amendments or comparable ethical standards.

\section{Informed consent}

Informed consent was obtained from all individual participants included in the study.

\section{Note}

1. One child, aged 2.9 years, was slightly outside of the eligibility criteria but was included in the study.

\section{Disclosure Statement}

No potential conflict of interest was reported by the authors.

\section{Funding}

The Incredible Years Ireland Study was funded by Archways with support from The Atlantic Philanthropies.

\section{Notes on contributors}

Yvonne Leckey is Researcher, Centre for Mental Health \& Community Research, Maynooth University, Ireland.

Prof. Sinead McGilloway is Director, Centre for Mental Health \& Community Research, Maynooth University, Ireland.

Dr Grainne Hickey is Research Programme Manager, Centre for Mental Health \& Community Research, Maynooth University, Ireland.

Mairead Bracken-Scally is Postdoctoral Research Fellow, Trinity Centre for Practice and Healthcare Innovation, Trinity College, Dublin, Ireland.

Paul Kelly belongs to School of Nursing \& Midwifery, Trinity College, Dublin, Ireland.

Mairead Furlong is Research Programme Coordinator, Centre for Mental Health \& Community Research, Maynooth University, Ireland.

\section{ORCID}

Yvonne Leckey (D) http://orcid.org/0000-0001-6257-8105

\section{References}

Abidin, R. R. (1990). Parenting stress index-short form. Charlottesville, VA: Pediatric Psychology Press. 
Antshel, K. M., \& Remer, R. (2003). Social skills training in children with attention deficit hyperactivity disorder: A randomized-controlled clinical trial. Journal of Clinical Child and Adolescent Psychology, 32(1), 153-165.

Arnold, D. S., O’leary, S. G., Wolff, L. S., \& Acker, M. M. (1993). The Parenting Scale: A measure of dysfunctional parenting in discipline situations. Psychological Assessment, 5(2), 137-144.

Azevedo, A. F., Seabra-Santos, M. J., Gaspar, M. F., \& Homem, T. C. (2013, October). The Incredible Years basic parent training for Portuguese preschoolers with $\mathrm{AD} / \mathrm{HD}$ behaviors: Does it make a difference?. Child \& Youth Care Forum, 42(5), 403-424.

Barkley, R. A. (2002). Major life activity and health outcomes associated with attention-deficit/ hyperactivity disorder. The Journal of Clinical Psychiatry, 63(Suppl 12), 10-15.

Barkley, R. A., Murphy, K. R., \& Fischer, M. (2008). ADHD in adults: What the science says. New York, NY: Guilford Publications.

Bywater, T., Hutchings, J., Daley, D., Whitaker, C., Yeo, S. T., Jones, K., ... Edwards, R. T. (2009). Long-term effectiveness of a parenting intervention for children at risk of developing conduct disorder. The British Journal of Psychiatry, 195(4), 318-324.

Chronis, A. M., Chacko, A., Fabiano, G. A., Wymbs, B. T., \& Pelham, W. E. (2004). Enhancements to the behavioral parent training paradigm for families of children with ADHD: Review and future directions. Clinical Child and Family Psychology Review, 7(1), 1-27.

Cohen, J. (1988). Statistical power analysis for the behavioral sciences (2nd ed.). Hillsdale, NJ: Lawrence Erlbaum Associates.

Conners, C. K. (2008). Conners third edition (Conners 3). Los Angeles, CA: Western Psychological Services.

Daley, D., Jones, K., Hutchings, J., \& Thompson, M. (2009). Attention deficit hyperactivity disorder in pre-school children: Current findings, recommended interventions and future directions. Child: Care, Health and Development, 35(6), 754-766.

Daley, D., van der Oord, S., Ferrin, M., Danckaerts, M., Doepfner, M., Cortese, S., \& Sonuga-Barke, E. J. S. (2014). Behavioral interventions in attention-deficit/hyperactivity disorder: A MetaAnalysis of randomized controlled trials across multiple outcome domains. Journal of the American Academy of Child \& Adolescent Psychiatry. doi:10.1016/j.jaac.2014.05.013

de Boo, G. M., \& Prins, P. J. (2007). Social incompetence in children with ADHD: Possible moderators and mediators in social-skills training. Clinical Psychology Review, 27, 78-97.

Fabiano, G. A., Pelham, W. E., Coles, E. K., Gnagy, E. M., Chronis-Tuscano, A., \& O’Connor, B. C. (2009). A meta-analysis of behavioral treatments for attention-deficit/hyperactivity disorder. Clinical Psychology Review, 29(2), 129-140.

Furlong, M., McGilloway, S., Bywater, T., Hutchings, J., Smith, S. M., \& Donnelly, M. (2013). Cochrane review: Behavioural and cognitive-behavioral group-based parenting programs for early-onset conduct problems in children aged 3 to 12 years (review). Evidence-Based Child Health: A Cochrane Review Journal, 8(2), 318-692.

Gardner, F., Burton, J., \& Klimes, I. (2006). Randomised controlled trial of a parenting intervention in the voluntary sector for reducing child conduct problems: Outcomes and mechanisms of change. Journal of Child Psychology and Psychiatry, 47(11), 1123-1132.

Goodman, R. (1997). The strengths and difficulties questionnaire: A research note. Journal of Child Psychology and Psychiatry, 38(5), 581-586.

Hannesdottir, D. K., Ingvarsdottir, E., \& Bjornsson, A. (2017). The OutSMARTers program for children with ADHD: A pilot study on the effects of social skills, self-regulation, and executive function training. Journal of Attention Disorders, 21(4), 353-364.

Harpin, V. A. (2005). The effect of ADHD on the life of an individual, their family, and community from preschool to adult life. Archives of Disease in Childhood, 90(suppl. 1), i2-i7.

Hartman, R., Stage, S., \& Webster-Stratton, C. (2003). A growth curve analysis of parent training outcomes: Examining the influence of child risk factors (inattention, impulsivity and hyperactivity problems). Journal of Child Psychology and Psychiatry, 44, 388-398.

Harvey, E., Danforth, J. S., Ulaszek, W. R., \& Eberhardt, T. L. (2001). Validity of the parenting scale for parents of children with attention-deficit/hyperactivity disorder. Behaviour Research and Therapy, 39(6), 731-743. 
Hoza, B. (2007). Peer functioning in children with ADHD. Journal of Pediatric Psychology, 32(6), 655-663.

Jones, K., Daley, D., Hutchings, J., Bywater, T., \& Eames, C. (2007). Efficacy of the IY basic parent training programme as an early intervention for children with conduct problems and ADHD. Child: Care, Health and Development, 33(6), 749-756.

Larson, K., Russ, S. A., Kahn, R. S., \& Halfon, N. (2011). Patterns of comorbidity, functioning, and service use for US children with ADHD, 2007. Pediatrics, 127(3), 462-470. doi:10.1542/peds. 2010-0165

Larsson, B., Fossum, S., Clifford, G., Drugli, M. B., Handegård, B. H., \& Mørch, W. T. (2009). Treatment of oppositional defiant and conduct problems in young Norwegian children. European Child \& Adolescent Psychiatry, 18(1), 42-52.

Lee, P. C., Niew, W. I., Yang, H. J., Chen, V. C. H., \& Lin, K. C. (2012). A meta-analysis of behavioral parent training for children with attention deficit hyperactivity disorder. Research in Developmental Disabilities, 33(6), 2040-2049.

McGilloway, S., Mhaille, G. N., Bywater, T., Furlong, M., Leckey, Y., Kelly, P., ... Donnelly, M. (2012). A parenting intervention for childhood behavioral problems: A randomized controlled trial in disadvantaged community-based settings. Journal of Consulting and Clinical Psychology, 80(1), 116-127.

McKee, T. E., Harvey, E., Danforth, J. S., Ulaszek, W. R., \& Friedman, J. L. (2004). The relation between parental coping styles and parent-child interactions before and after treatment for children with ADHD and oppositional behaviour. Journal of Clinical Child and Adolescent Psychology, 33(1), 158-168.

Menting, A. T., de Castro, B. O., \& Matthys, W. (2013). Effectiveness of the incredible years parent training to modify disruptive and prosocial child behaviour: A meta-analytic review. Clinical Psychology Review, 33(8), 901-913.

Mikami, A. Y., \& Lorenzi, J. (2011). Gender and conduct problems predict peer functioning among children with attention-deficit/hyperactivity disorder. Journal of Clinical Child \& Adolescent Psychology, 40(5), 777-786.

Modesto-Lowe, V., Danforth, J. S., \& Brooks, D. (2008). ADHD: Does parenting style matter?. Clinical Pediatrics, 47(9), 865-872.

National Institute for Health and Clinical Excellence. (2008). Promoting children's social and emotional well-being in primary education. London: Author.

National Institute for Health and Clinical Excellence. (2009). Diagnosis and management of ADHD in children, young people and adults. London: Author.

Nixon, E. (2001). The social competence of children with attention deficit hyperactivity disorder: A review of the literature. Child Psychology and Psychiatry Review, 6(4), 172-180.

Olfson, M., Gameroff, M. J., Marcus, S. C., \& Jensen, P. S. (2003). National trends in the treatment of attention deficit hyperactivity disorder. American Journal of Psychiatry, 160(6), 1071-1077.

Polanczyk, G., de Lima, M. S., Horta, B. L., Biederman, J., \& Rohde, L. A. (2007). The worldwide prevalence of ADHD: A systematic review and metaregression analysis. American Journal of Psychiatry, 164(6), 942-948.

Polderman, T., Boomsma, D., Bartels, M., Verhulst, F., \& Huizink, A. (2010). A systematic review of prospective studies on attention problems and academic achievement. Acta Psychiatrica Scandinavica, 122, 271-284.

Scott, S., Webster-Stratton, C., Spender, Q., Doolan, M., Jacobs, B., \& Aspland, H. (2001). Multicentre controlled trial of parenting groups for childhood antisocial behaviour in clinical practice. Commentary: Nipping conduct problems in the bud. BMI, 323(7306), 3-4.

Sonuga-Barke, E. J. S., Brandeis, D., Cortese, S., Daley, D., Ferrin, M., Holtmann, M., ... European ADHD Guidelines Group (2013). Nonpharmacological interventions for ADHD: Systematic review and meta-analyses of controlled trials of dietary and psychological treatments. The American Journal of Psychiatry, 170(3), 275-289.

Sonuga-Barke, E. J. S., Thompson, M., Abikoff, H., Klein, R., \& Brotman, L. M. (2006). Nonpharmacological interventions for preschoolers with ADHD: The case for specialized parent training. Infants \& Young Children, 19(2), 142-153. 
Spence, S. H. (2003). Social skills training with children and young people: Theory, evidence and practice. Child and Adolescent Mental Health, 8(2), 84-96.

Sprague, R. L., Barnes, K. R., \& Werry, J. S. (1970). Methylphenidate and thioridazine: Learning, reaction time, activity, and classroom behaviour in disturbed children. American Journal of Orthopsychiatry, 40(4), 615-628.

Stewart-Brown, S., Patterson, J., Mockford, C., Barlow, J., Klimes, I., \& Pyper, C. (2004). Impact of a general practice based group parenting programme: Quantitative and qualitative results from a controlled trial at 12 months. Archives of Disease in Childhood, 89(6), 519-525.

Tarver, J., Daley, D., \& Sayal, K. (2014). Attention-deficit hyperactivity disorder (ADHD): An updated review of the essential facts. Child: Care, Health and Development, 40(6), 762-774.

Taylor, E., Döpfner, M., Sergeant, J., Asherson, P., Banaschewski, T., Buitelaar, J., \& Zuddas, A. A. (2004). European clinical guidelines for hyperkinetic disorder-first upgrade. European Child \& Adolescent Psychiatry, 13(1), i7-i30.

Tettenborn, M., Prasad, S., Poole, L., Steer, C., Coghill, D., Harpin, V., ... Myttas, N. (2008). The provision and nature of ADHD services for children/adolescents in the UK: Results from a nationwide survey. Clinical Child Psychology and Psychiatry, 13(2), 287-304.

Webster-Stratton, C. (1998). Preventing conduct problems in head start children: Strengthening parenting competencies. Journal of Consulting and Clinical Psychology, 66(5), 715-730.

Webster-Stratton, C. (2005). The Incredible Years parents, teachers, and children training series: Early intervention and prevention programs for young children. In P. S. Jensen, \& E. D. Hibbs (Eds.), Psychosocial treatments for child and adolescent disorders (pp. 507-555). Washington, DC: American Psychological Association.

Webster-Stratton, C. (2007). The Incredible Years parent training manual: BASIC program (3rd ed.). Seattle, WA: Incredible Years.

Webster-Stratton, C., \& Reid, J. M. (2008). Adapting the Incredible Years child dinosaur social, emotional, and problem-solving intervention to address co-morbid diagnoses and family risk factors. Journal of Children's Services, 3, 17-30.

Webster-Stratton, C., Reid, J. M., \& Hammond, M. (2004). Treating children With early-onset conduct problems: Intervention outcomes for parent, child, and teacher training. Journal of Clinical Child \& Adolescent Psychology, 33, 105-124.

Webster-Stratton, C., \& Reid, M. J. (2003). Treating conduct problems and strengthening social and emotional competence in young children: The dina dinosaur treatment program. Journal of Emotional and Behavioral Disorders, 11(3), 130-143.

Webster-Stratton, C., \& Reid, M. J. (2010). The Incredible Years Parents, Teachers, and Children Training Series: A multifaceted treatment approach for young children. In J. Weisz \& A. Kazdin (Eds.), Evidence based psychotherapies for children and adolescents (2nd ed.). New York: Guilford Publications.

Webster-Stratton, C., \& Reid, M. J. (2014). Tailoring the Incredible Years parent, teacher, and child interventions for young children with ADHD. In J. K. Ghuman \& H. S. Ghuman (Eds.), ADHD in preschool Children: Assessment and treatment (pp. 113-131). Oxford: Oxford University Press.

Webster-Stratton, C., Jamila Reid, M., \& Stoolmiller, M. (2008). Preventing conduct problems and improving school readiness: Evaluation of the Incredible Years teacher and child training programs in high-risk schools. Journal of Child Psychology and Psychiatry, 49(5), 471-488.

Webster-Stratton, C., Reid, M. J., \& Beauchaine, T. J. (2011). Combining parent and child training for young children with ADHD. Journal of Clinical Child \& Adolescent Psychology, 40, 191-203.

Werry, J. S. (1968). Developmental hyperactivity. Pediatric Clinics of North America, 15(3), 581599.

Zuvekas, S. H., Vitiello, B., \& Norquist, G. S. (2006). Recent trends in stimulant medication use among US children. American Journal of Psychiatry, 163(4), 579-585.

Zwi, M., Jones, H., Thorgaard, C., York, A., \& Dennis, J. A. (2011). Parent training interventions for attention deficit hyperactivity disorder (ADHD) in children aged 5 to 18 years. The Cochrane Library, (12), CD003018. doi:10.1002/14651858.CD003018.pub3 